http://jmscr.igmpublication.org/home/ ISSN (e)-2347-176x ISSN (p) 2455-0450

crossref DOI: https://dx.doi.org/10.18535/jmscr/v7i11.42

\author{
D) Journal Of Medical Science And Clinical Research \\ IGM Publication \\ An Official Publication of IGM Publication
}

\title{
Study of Platelet Indices in Ischemic Stroke Patients
}

\author{
Authors \\ Dr J. Punekar ${ }^{1 *}$, Dr Brijraj Shukla ${ }^{2 *}$ \\ ${ }^{1,2}$ Department of Medicine, Netaji Subhash Chandra Bose Medical College, Jabalpur, (M.P)
}

\begin{abstract}
Introduction: Cerebrovascular diseases are one of the most general causes of morbidity and mortality. Ischemic stroke occurs when blood flow in a vessel is compromised by atherosclerosis plagues and it ultimately leads to thrombus formation. Platelets plays an essential role in the pathophysiology of ischemic stroke by developing intravascular thrombus after erosion or rupture of atherosclerotic plaques. The involvement of blood clot in ischemic stroke demands for effective and constant monitoring of haemostatic parameters such as platelet components in stroke patients in order to properly manage and treat them.

Methods \& Material: Considering the best availability of the patients by reviewing the previous records of this health facility to achieve the maximum sample size we randomly screen all patients who have fulfill the inclusion and exclusion criteria and ready to give the written consent. After all aseptic precautions $2 \mathrm{ml}$ of blood sample was obtained from antecubital vein of the patient within 48 hours of onset of signs and symptoms of ischemic stroke. Samples were collected in EDTA vials, kept at room temperature. The printout reports of samples fed to MINDRAY-BC 3600 Autoanalyser and collected and analyzed.

Results: There was direct relationship of MPV, PC and PLCR with severity of ischemic stroke and inverse relationship of PDW and PCT with severity of ischemic stroke. PC and PLCR were higher in patient with ischemic stroke but PC showed not significant change whereas PLCR showed significant abnormal changes in ischemic stroke patient.

Conclusions: Platelet indices are marker of platelet function. Its utility as a risk factor in cases of coronary artery disease is well known. This study shows that MPV is higher in patients of acute ischemic stroke / TIA, hence, it can be regarded as an independent risk factor for ischemic stroke / TIA. Elevated mean platelet volume is associated with more severe morbidity and worse outcome in patients with acute ischemic stroke / TIA. There was direct relationship of MPV, PC and PLCR with severity of ischemic stroke and inverse relationship of PDW and PCT with severity of ischemic stroke.
\end{abstract}

\section{Introduction}

Cerebrovascular diseases are one of the most general causes of morbidity and mortality. They cause 200,000 deaths each year in the united states and it is a major cause of disability nowadays. ${ }^{1}$ Ischemic stroke occurs when blood flow in a vessel is compromised by atherosclerosis plagues and it ultimately leads to thrombus formation. Ischaemic stroke can also occur as a result of blockage of a blood vessel supplying blood to the brain resulting upon thrombosis, cerebral hypoperfusion, thromboembolism or atherosclerotic plaque. $^{2}$

Platelets plays an essential role in the pathophysiology of ischemic stroke by developing intravascular thrombus after erosion or rupture of atherosclerotic plaques. ${ }^{3}$ The involvement of blood clot in ischemic stroke demands for 
effective and constant monitoring of haemostatic parameters such as platelet components in stroke patients in order to properly manage and treat them. ${ }^{4}$

The novel platelet indices such as mean platelet component, platelet count and platelet distribution width have been used as prospective platelet activation markers.

The aim is to study the platelet indices in ischemic stroke. The Primary objective is to study the association between Platelet indices and Ischemic Stroke and Secondary objective is to determine the role of platelet indices in the severity and outcome of Ischemic Stroke within 7 days.

\section{Material and Methods \\ Sample Size}

- Sample size estimated based on the finding reported in a study carried out on platelets and stroke by Smith et al 1990.The mean difference of platelets among stroke and healthy control subjects was revealed $57.14 \pm 8.14$. Therefore we assumed this difference of mean platelets count with absolute precision of 8 which accumulates the minimum required sample size 150 each for stroke and control participants in the study. The sample size was estimated using following formula for simple random sampling -

$$
\mathrm{n}=\mathrm{z} 2 \mathrm{pq} / 12
$$

Where -

$\mathrm{n}=$ sample size, $\mathrm{z}=1.96$ (considering 0.05 alpha, 95\% confidence limits and $80 \%$ beta), $\mathrm{p}=$ Probability of mean difference of platelets count among stroke and control subject and it was assumed 57 with 8 absolute precision i.e. $57 \pm 8=49$ to 65 occurrence or concordance of results

$\mathrm{q}=1-\mathrm{p}$

$l=$ marginal error $($ precession $)=8$

Sampling- Considering the best availability of the patients by reviewing the previous records of this health facility to achieve the maximum sample size we randomly screen all patients who have fulfill the inclusion and exclusion criteria and ready to give the written consent.

\section{Inclusion Criteria}

Patient willing to be a part of study, Patient presenting with acute ischemic stroke with definitive signs of neurological deficit and ischemic stroke that is proven by CT brain.

\section{Exclusion Criteria}

Patient not willing, Hemorrhagic stroke, Thrombocytopenia, Known case of hereditary or other disorder of platelet.

\section{Data Collection - Tools:}

- Patients with acute ischemic stroke .

- Various signs to recognize ischemic stroke patients include non contrast CT

\section{Technique Used}

With aseptic precaution $2 \mathrm{ml}$ blood sample from anticubital vein of acute ischemic patient was taken in Ethylene Diamine Tetra Acetic acid.

- Platelet Indices in acute ischemic patient were estimated and correlated with the prognosis of the condition. Platelet Indices is commonly measured by Complete Blood Count by automated analyzer.

\section{Laboratory Methods}

Complete Blood Count

- Other routines test -

Blood sugar, Liver Function Test, Renal Function Test, Electrocardiography

\section{Ethical Issues}

This study were conducted after getting written consent from the patient. This is an observational study and techniques used which were noninvasive, there was no ethical issues involved.

\section{Procedure}

- After all aseptic precautions $2 \mathrm{ml}$ of blood sample was obtained from antecubital vein of the patient within 48 hours of onset of signs and symptoms of ischemic stroke. Samples were collected in EDTA vials, kept at room temperature. The printout reports of samples fed to MINDRAY-BC 
3600 Autoanalyser and collected and analyzed.

- MINDRAY-BC 3600 uses autoanalyser for calculating different haematological parameters. The results of all the patients were pooled and various platelet indices were obtained.

\section{Modified Rankin's Scale Used to Assess Clinical Severity of Stroke \\ Score Description}

0 - No symptoms at all

1 - No significant disability despite symptoms; able to carry out all usual duties and activities

2 - Slight disability; unable to carry out all previous activities, but able to look after own affair without assistance

3 - Moderate disability; requiring some help, but able to walk without assistance

4 - Moderately severe disability; unable to walk without assistance and unable to attend to own bodily needs without assistance.

5 - Severe disability; bedridden, incontinent and requiring constant nursing care and attention

6 - Dead

\section{Statistical Analysis}

- All the records were rechecked for their completeness and consistencies. Non numeric entries were coded numerically into nominal/ordinal distribution before analysis. Categorical variables were summarized in frequency and percent distribution and Chi-square or Fishers exact test was performed as appropriate.

- Continuous variable were analyzed using mean \pm sd or median with inter quartile range as appropriate. Mean difference between two independent groups were analyzed by using independent t-test after normalized the distribution otherwise nonparamatric test were applied.

- Odds ratio with $95 \%$ confidence limits were analyzed to find out the potential risk factors. Receiver operating characteristic curv (ROC) analysis also be performed to find out the best cutoff value. For test the null hypothesis critical value for alpha 0.05 (type I error) and 95\% confidence limit were applied.

\section{Results}

\section{MPV/PC Ratio in Cases and Controls}

Table-1 showed mean value of MPV/PC ratio in cases was $0.06 \pm 0.03$ and mean value in control was $0.03 \pm 0.02$ which was statistically significant. $(\mathrm{p}<0.0001 ; \mathrm{t}=7.50)$.

\begin{tabular}{|l|c|c|}
\hline MPV/PC & Mean & Standard Deviation \\
\hline Control & 0.03 & 0.02 \\
\hline Case & 0.06 & 0.03 \\
\hline
\end{tabular}

Table -2 Differences in frequency distribution between severity score and MPV

\begin{tabular}{|l|c|c|c|c|}
\hline \multirow{2}{*}{ Severety Score } & \multicolumn{2}{|c|}{ MPV } & \multirow{2}{*}{ Total } \\
\cline { 3 - 4 } & Count & Normal & Abnormal & \\
\cline { 2 - 4 } 1 & $\%$ within MPV & $13.90 \%$ & $0.00 \%$ & $10.70 \%$ \\
\hline \multirow{2}{*}{3} & Count & 28 & 0 & 28 \\
\cline { 2 - 5 } & $\%$ within MPV & $24.30 \%$ & $0.00 \%$ & $18.70 \%$ \\
\hline \multirow{2}{*}{4} & Count & 32 & 0 & 32 \\
\cline { 2 - 5 } & $\%$ within MPV & $27.80 \%$ & $0.00 \%$ & $21.30 \%$ \\
\hline \multirow{2}{*}{5} & Count & 38 & 24 & 62 \\
\cline { 2 - 5 } & $\%$ within MPV & $33.00 \%$ & $68.60 \%$ & $41.30 \%$ \\
\hline \multirow{2}{*}{6} & Count & 1 & 11 & 12 \\
\cline { 2 - 5 } & $\%$ within MPV & $0.90 \%$ & $31.40 \%$ & $8.00 \%$ \\
\hline \multirow{2}{*}{ Total } & Count & 115 & 35 & 150 \\
\cline { 2 - 5 } & $\%$ within MPV & $100.00 \%$ & $100.00 \%$ & $100.00 \%$ \\
\hline
\end{tabular}

Table 2 showed out of 150 cases, maximum number of cases that is $62(41.30 \%)$ showed severity score 5 , from which 24 cases showed abnormal MPV, that was statistically significant. (Chi square value $=62.65 ; \mathrm{p}=<0.0001$ ) 
Graph - 2 Associations between Severity Score and MPV

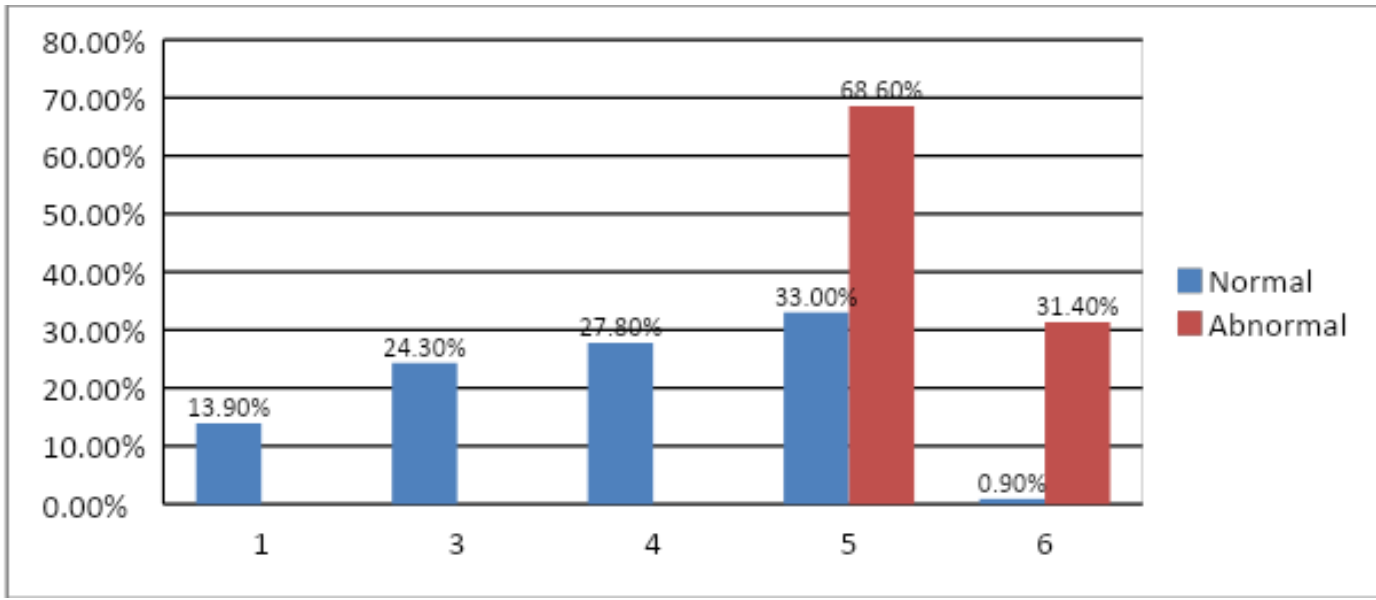

Table No. - 3 Association between Severity Score and PC

\begin{tabular}{|l|c|c|c|c|}
\hline \multirow{2}{*}{ Severety Score } & \multicolumn{2}{|c|}{ PC } & Total \\
\cline { 3 - 5 } & Count & Normal & Abnormal & \\
\cline { 2 - 5 } 1 & $\%$ within PC & $14.40 \%$ & 1 & 16 \\
\hline \multirow{2}{*}{3} & Count & 26 & $2.20 \%$ & $10.70 \%$ \\
\cline { 2 - 5 } & $\%$ within PC & $25.00 \%$ & $4.30 \%$ & $18.70 \%$ \\
\hline \multirow{2}{*}{4} & Count & 17 & 15 & 32 \\
\cline { 2 - 5 } & $\%$ within PC & $16.30 \%$ & $32.60 \%$ & $21.30 \%$ \\
\hline \multirow{2}{*}{5} & Count & 41 & 21 & 62 \\
\cline { 2 - 5 } & $\%$ within PC & $39.40 \%$ & $45.70 \%$ & $41.30 \%$ \\
\hline \multirow{2}{*}{6} & Count & 5 & 7 & 12 \\
\cline { 2 - 5 } & $\%$ within PC & $4.80 \%$ & $15.20 \%$ & $8.00 \%$ \\
\hline \multirow{2}{*}{ Total } & Count & 104 & 46 & 150 \\
\cline { 2 - 5 } & $\%$ within PC & $100.00 \%$ & $100.00 \%$ & $100.00 \%$ \\
\hline
\end{tabular}

Table 3 showed out of 150 cases, maximum abnormal PC, that was statistically significant. number of cases that is $62(41.30 \%)$ showed (Chi square value $=20.30 ; p=<0.0001)$ severity score 5, from which 21 cases showed

Graph - 3 Association Between Severity Score and PC

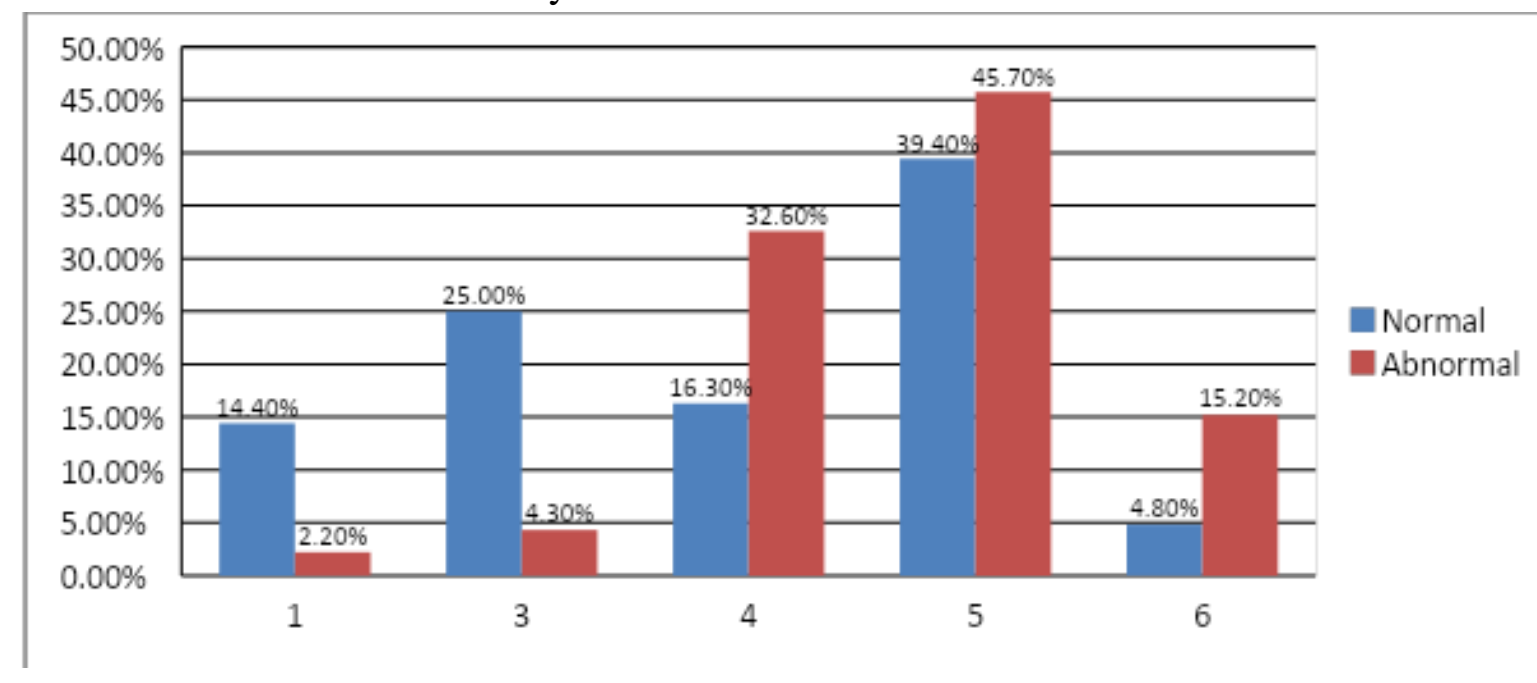


Table No. -4 Association between Severity Score and PLCR

\begin{tabular}{|l|c|c|c|c|}
\hline \multirow{2}{*}{ Severity Score } & \multicolumn{2}{|c|}{ PLCR } & \multirow{2}{*}{ Total } \\
\cline { 3 - 5 } & Count & Normal & Abnormal & \\
\hline \multirow{2}{*}{1} & $\%$ within PLCR & $14.80 \%$ & 0 & 16 \\
\hline \multirow{2}{*}{3} & Count & 27 & $0.00 \%$ & $10.70 \%$ \\
\cline { 2 - 5 } & $\%$ within PLCR & $25.00 \%$ & $2.40 \%$ & $18.70 \%$ \\
\hline \multirow{2}{*}{4} & Count & 31 & 1 & 32 \\
\cline { 2 - 5 } & $\%$ within PLCR & $28.70 \%$ & $2.40 \%$ & $21.30 \%$ \\
\hline \multirow{2}{*}{5} & Count & 26 & 36 & 62 \\
\hline \multirow{2}{*}{6} & $\%$ within PLCR & $24.10 \%$ & $85.70 \%$ & $41.30 \%$ \\
\hline \multirow{2}{*}{ Total } & Count & 8 & 4 & 12 \\
\cline { 2 - 5 } & $\%$ within PLCR & $7.40 \%$ & $9.50 \%$ & $8.00 \%$ \\
\cline { 2 - 4 } & Count & 108 & 42 & 150 \\
\hline
\end{tabular}

Table 4 showed out of 150 cases, 62 csaes statistically significant. (Chi square value $=52.30$; (41.30\%) showed severity score 5, from which 36 $\mathrm{p}=<0.0001)$ cases showed abnormal PLCR, that was

Graph No. - 4 Association between Severity Score and PLCR

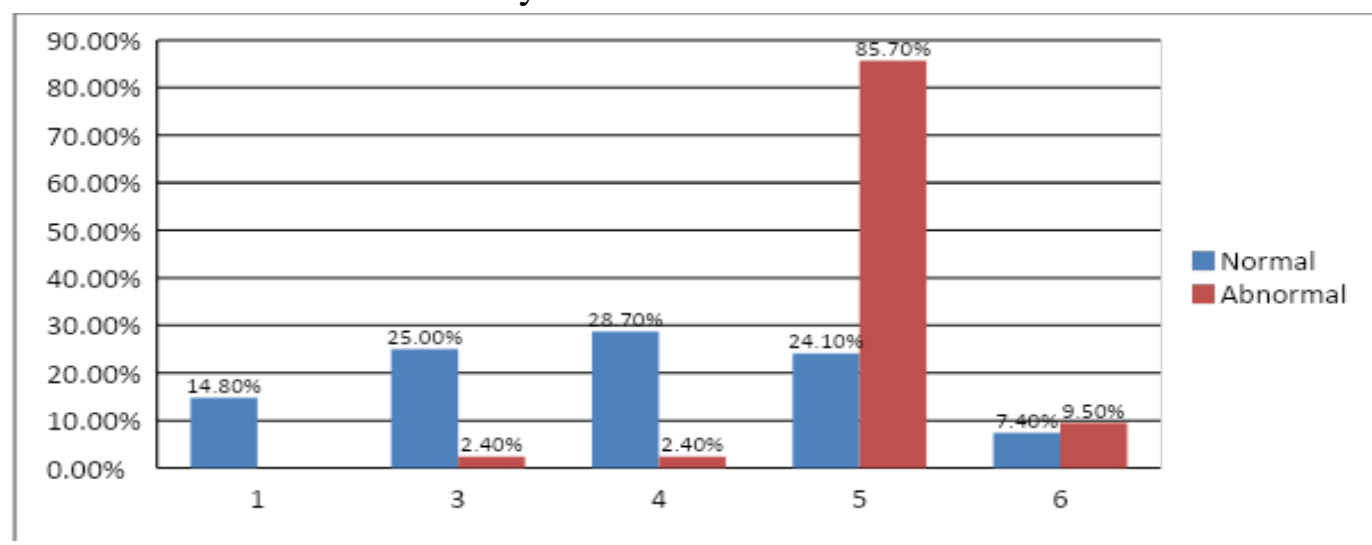

Table -5 Correlation Coefficient of Severity Score and Platelet Indices

\begin{tabular}{|l|c|c|c|}
\hline S. No. & Platelet indices variables & Correlation coefficient $(\mathrm{r})$ & P value \\
\hline 1 & MPV & +0.73 & $<0.0001$ \\
\hline 2 & PC & +0.08 & 0.33 \\
\hline 3 & PDW & -0.10 & 0.22 \\
\hline 4 & PLCR & +0.24 & 0.003 \\
\hline 5 & PCT & -0.06 & 0.48 \\
\hline
\end{tabular}

Table -5 showed there was direct (+) relationship of MPV, PC and PLCR with severity of ischemic stroke and inverse relationship of PDW and PCT with severity of ischemic stroke. MPV and PLCR showed significant $\mathrm{p}$ value that is $<0.0001$ and 0.003 respectively where as PC, PDW and PCT showed not significant $\mathrm{p}$ value that is $0.33,0.22$ and 0.48 respectively.

Table -6 Associations of Platelet Indices with Outcome of Ischemic Stroke

\begin{tabular}{|l|c|c|c|c|}
\hline \multirow{2}{*}{$\begin{array}{l}\text { Platelet } \\
\text { indices }\end{array}$} & \multicolumn{3}{|c|}{ Outcome } \\
\cline { 2 - 5 } & \multicolumn{3}{|c|}{ Death } & \multicolumn{2}{c|}{ Survive } \\
\cline { 2 - 5 } & Mean & Standard Deviation & Mean & Standard Deviation \\
\hline MPV & 15.32 & 1.71 & 11.01 & 1.15 \\
\hline PC & 284.83 & 146.69 & 248.97 & 102.80 \\
\hline PDW & 15.91 & 0.39 & 16.41 & 2.13 \\
\hline PLCR & 39.53 & 18.40 & 40.02 & 9.16 \\
\hline PCT & 1.74 & 0.30 & 1.85 & 0.52 \\
\hline
\end{tabular}


Table-6 showed cases with poor outcome (death) had increased mean value of MPV $(15.32 \pm 1.71)$ and PC $(284.83 \pm 146.69)$ than cases with good outcome (survivor) where the mean value of MPV $(11.01 \pm 1.15)$ and PC $(248.97 \pm 102.80)$, whereas there is no significant changes in PDW, PCT and PLCR.

\section{Discussion}

The present study was conducted in the Department of Medicine, N.S.C.B. Medical College and Hospital, Jabalpur from 1st March 2017 to 31st August 2018 to study the association of platelet indices with ischemic stroke and to determine the role of platelet indices in the severity and outcome of ischemic stroke within 7 days.

\section{Relationship of MPV/PC Ratio in Cases and Controls}

In the present study table 1 shows, mean value of MPV/PC ratio in cases was $0.06 \pm 0.03$ and mean value in control was $0.03 \pm 0.02$ which was statistically significant $(\mathrm{p}<0.0001$.

This was in accordance with the study of Elsayed $\mathrm{AM}$ et al ${ }^{5}$, where mean value of MPV/PC ratio in cases was $0.036 \pm 0.010$ and mean value in control was $0.030 \pm 0.007$ which was statistically significant $(\mathrm{p}=0.017)$.

\section{Difference in Frequency Distribution between} Severity Score and MPV

In the present study, table 2 shows, out of 150 cases, maximum number of cases that is 62 $(41.30 \%)$ showed severity score 5 , from which 24 cases showed abnormal MPV, that was statistically significant.

This was similar to study of Sridharan $\mathrm{M}$ et al ${ }^{6}$, where 28 cases showed severity score 3-6 and that was statistically significant.

Arevalo-Lorido JC et al ${ }^{7}$ showed modified Rankin Scale score of 3 to 6, was significantly higher $(\mathrm{P}<.0004)$ by greater third of MPV. They concluded that MPV may be an easily available predictor for the prognosis in patients with acute ischemic stroke. This was comparable with the present study.
Another study by Greisenegger $\mathrm{S}$ et $\mathrm{al}^{8}$ showed elevated MPV associated with a worse outcome in patients with acute ischemic cerebrovascular events. . The result showed that patient with highest quintile of MPV (11.3 to $15.3 \mathrm{fl}$ ) had a significantly higher risk of suffering a severe stroke, defined as modified Rankin scale score of 3 to 6 , compared with patients with patients within the lowest quintile. This was comparable with the present study.

Another study by Murlidharan $\mathrm{K}$ et $\mathrm{al}^{9}$ aimed to assessed mean platelet volume in ischemic stroke. Patients with MRS score of 5 and 6 were declared as very poor outcome and MRS of 3 and 4 as poor outcome. Patients with MRS 0 and 1 were considered as good outcome. There was a linear relation with MPV and severity of ischemic stroke i.e. as the MPV increases the severity of stroke increases. This was comparable with the present study.

Another study by Ghahremanfard F, et $\mathrm{al}^{10}$ concluded MPV was associated with ischemic stroke severity and has a high value for discriminating severe from mild ischemic stroke, which was same as our study.

Difference in Frequency Distribution between Severity Score and PC

In our study table 3 shows, out of 150 cases, maximum number of cases that is $62(41.30 \%)$ showed severity score 5, from which 21 cases showed abnormal PC, that was statistically significant.

This was in accordance with the study of MaydaDomac F et al ${ }^{11}$, where PC was found to be statistically significant in patient with ischemic stroke who have poor prognosis or died.

\section{Difference in Frequency Distribution between} Severity Score and PLCR

In the present study table 4 shows, out of 150 cases, maximum number of cases that is 62 $(41.30 \%)$ showed severity score 5, from which 36 cases showed abnormal PLCR, that was statistically significant. 
There was no study done till now that showed the association of PLCR with severity of ischemic stroke. Hence, further studies will be required.

\section{Correlation Coefficient of Severity Score and} Platelet Indices

In The study table 5 shows, that there was direct relationship of MPV, PC and PLCR with severity of ischemic stroke and inverse relationship of PDW and PCT with severity of ischemic stroke.

This was similar to the study of Muralidharan K et al $^{9}$, where there was a linear relation with MPV and severity of ischemic stroke. As the MPV increases the severity of stroke increases.

Another study by Mathur $\mathrm{M}$ et al ${ }^{12}$, showed a statistically significant correlation between clinical severity of stroke and mean platelet volume. This was comparable with the present study.

\section{Association of Platelet Indices with Severity of Ischemic Stroke}

Table 6 showed cases with poor outcome (death) had increased mean value of MPV (15.32 \pm 1.71$)$ and PC $(284.83 \pm 146.69)$ than cases with good outcome (survivor) where the mean value of MPV $(11.01 \pm 1.15)$ and PC $(248.97 \pm 102.80)$, whereas there is no significant changes in PDW, PCT and PLCR.

This was in accordance with the study of MaydaDomac F et al ${ }^{11}$, where MPV and PC considered an early and important predictor for the prognosis and outcome of ischemic stroke.

Another study done by Arevalo-Lorido JC et al ${ }^{7}$ showed the association of MPV with a greater mortality and morbidity in patients with acute stroke, and with a poor functional outcome in these patients. This was as comparable to our study.

Another study by Greisenegger $\mathrm{S}$ et $\mathrm{al}^{8}$ showed that elevated MPV is associated with a worse outcome for acute ischemic stroke. This was similar to our study.

\section{Conclusion}

Platelet indices are marker of platelet function. Its utility as a risk factor in cases of coronary artery disease is well known.

This study shows that MPV is higher in patients of acute ischemic stroke / TIA, hence, it can be regarded as an independent risk factor for ischemic stroke / TIA. Elevated mean platelet volume is associated with more severe morbidity and worse outcome in patients with acute ischemic stroke / TIA.

There was direct relationship of MPV, PC and PLCR with severity of ischemic stroke and inverse relationship of PDW and PCT with severity of ischemic stroke.

PC and PLCR were higher in patient with ischemic stroke but PC showed not significant change whereas PLCR showed significant abnormal changes in ischemic stroke patient.

PDW and PCT were inversely related to severity of ischemic stroke but the change was not significant.

\section{References}

1. Neki NS, Minda N, Jain A. A study of association of mean platelet volume and ischemic stroke. Asian Pac. J. Health Sci, 2016; 3(4): 212-219

2. Donnan, G et al. Stroke. Lancet, 2008; 371: 1612-1623

3. Al Tameemi WF. Significance of platelet indices in patients with acute ischemic stroke. Iraqi J Med Sci, 2012; 10(4): 383389

4. Gideon CS, Ighida BF, Mgheoma EE. Changes in haematological parameters in stroke patients in port Harcourt, Nigeria. IJSR, 2016; 5(3): 912- 915

5. Elsayed A, et al. Mean platelet volume and mean platelet volume/ platelet count ratio as a risk stratification tool in the assessment of severity of acute ischemic stroke. Alexandria Journal of Medicine, 2017; 53: 67-70 
6. Sridharan M, et al. A prospective study of mean platelet volume in predicting stroke type and its severity. JMSCR, 2018; 6(3): 333-337

7. Arevalo-Lorido JC, et al. Mean platelet volume in acute phase of ischemic stroke, as predictor of mortality and functional outcome after 1 year. Journal of stroke and cerebrovascular diseases, 2013; 22(4):297303

8. Greisenegger $\mathrm{S}$ et al. Is elevated mean platelet volume associated with a worse outcome in patient with acute ischemic cerebrovascular events. Stroke,2004; 35: 1688-1691

9. Muralidharan K, Murugesan S, et al. A study of mean platelet volume levels in patients with ischemic stroke. J. Evid. Based Med. Healthc, 2016; 3(71): 38743877

10. Ghahremanfard F, et al. The relationship between mean platelet volume and severity of acute ischemic brain stroke. Neurosciences, 2013; 18(2):147-51

11. Mayda- Domac F, et al. Prognostic role of mean platelet volume and platelet count in ischemic and hemorrhagic stroke. Journal of stroke and cerebrovascular diseases, 2010; 19(1): 66-72

12. Mathur V, et al. A study on association of mean platelet volume and ischemic stroke.

IOSR-JDMS, 2018; 17(4):35-46. 